Matej NIKŠIČ

Stefania RAGOZINO

Alenka FIKFAK

\title{
EDITORIAL
}

\section{Public spaces and local life: Questioning the participatory approaches}

The socio-economic changes and the democratization processes that started to unroll across the eastern part of Europe three decades ago opened new questions and challenges to the existing urban planning systems across the continent. The prevailing spirit of optimism assumed that the changes would bring positive developments to various societal sub-systems, including urban planning, seen not merely as a technical discipline but also as a political process concerned with development of inhabited spaces (Abbot, 1996; Tewdwr-Jones and Thomas, 1998). The democratization of the urban planning system was interpreted as setting new standards for an equal input of citizens in urban (re)development processes (Smith, 1999; Akkerman et al, 2004). At the same time certain other major changes were taking place across the European continent and at the global scale at the turn of the millennium, such as the progress of neoliberal and profit oriented market environments and the decreasing powers of welfare states within the broader framework of globalization. The ideals of equitable distribution of wealth and equality of opportunities were largely replaced by the ideals of free trade, market deregulation, privatization, and decreased governmental spending in social affairs, while the role of the states in neoliberal systems largely changed from regulatory into that of a notary, with the role of social reproduction largely reflecting the logic of capitalist production (Smith, 2002; Tasan-Kok and Baeten, 2012).

Under those conditions, it became easier to consider the democratic principles and consensual decision making in urban development at the theoretical level rather than in practice, despite the development of new technologies that could technically support democratization processes (Hamilton, 2005; Ertio, 2015; Beebeejaun, 2016; Sennett, 2017). When it came to everyday experiences and practices, some essential questions still needed to be answered: How to attain a decision making process that would be more reflective of the concrete needs and desires of heterogeneous urban populations? How to give the residents a true voice in decision making and how to mitigate the often contradicting interests that exist among them? And, last but not least, how to restore the demos - in its most noble ancient meaning - back into the centre of the decision making?

Urban public open spaces are highly contested areas where different interests and desires meet, which is why they are an ideal arena for considering such questions. Both their conception and their management are a matter of interest to the widest group of people, and they thus present an ideal testing bed of the level of societal ability for a democratic and consensual decision making as well as its tolerance towards its own diversity (Allmendinger and Haughton, 2011; 
Madanipour, 2016). In this special issue of the journal, we attempt to put the spotlight on different aspects of consensual decision making in spatial and urban planning in general, with particular focus on improvements of open public spaces with the direct or indirect participation of the regular users (i.e., both residents and other groups that inhabit and use them). We define public spaces as places of common good that can take different spatial forms (from small urban places to wider landscapes) as well as different forms of appearances (such as real places on the one hand and virtual places of a digital world on the other).

This volume was made possible thanks to the project Human Cities Challenging the City Scale 2014-2018, co-funded by the Creative Europe Programme of the European Union (Human Cities, 2008; 2010; 2014), addressing the issues of participatory approaches to contemporary urban design. The project focuses on bottom-up initiatives that self-organize in order to improve public spaces within their living environments. Important pillars of the project are research as well as experimental and educational activities related to public spaces and undertaken by twelve project partners from different European cities (Belgrade, Bilbao, Brussels, Cieszyn, Graz, Helsinki, Ljubljana, London, Milan, Saint-Etienne and Tallinn). The main goal is twofold: to help citizens develop an affinity for common urban spaces and strengthen their approaches to participatory re-design of these spaces, as well as to advance the theoretical foundations in the field of participatory provision of urban public spaces (Human Cities, 2014). The project also stresses the importance of shared values of community members in relation to public urban spaces, including empathy, wellbeing, intimacy, sustainability, conviviality, mobility, accessibility, imagination, leisure, aesthetics, sensoriality, solidarity, and respect. It emphasizes practicing more inclusive pathways for provision of public space, including engagement of marginal and minority groups, as well as experimenting with the long-term circular process in which public spaces' economic, social, and cultural dimensions could be adapted to cater for increasing solidarity, environmental concerns, and critical heritage studies.

Human Cities advocates the kind of critical and constructive dialogue on the processes related to issues of participatory approaches in contemporary urban design that equally involves researchers and practitioners, locals and guests. If the urban renewal process is to be undertaken in a participatory way, the regeneration strategies should be built around the values shared by local inhabitants and different stakeholders, such as NGOs and local businesses. This special issue with selected contributions from authors from different communities argues the need for reflection on the distinctive social and cultural values expressed in public spaces, resulting in the conclusion that place attachment and identification with places are encountered and experienced differently by different individuals and groups. It suggests that the main obstacle to a truly democratic approach to public space design and management is the neoliberal drift, promoting individual and strictly private interests and excluding instances of more vulnerable and disadvantageous groups.

The other aim of this volume is to critically review, select, explore, and rethink novel and original transdisciplinary texts related to:

- Cities facing austerity, crisis, and a variety of migration patterns;

- A civic response in the form of emerging practices of self-organization, social innovation, and planners' investments in building solidarity, hope, and trust;

- (Re)design and (re)organization of local environments with socially, economically, and ethnically more diverse communities in order to improve their capacity to act as a medium of social cohesion;

- Urban design solutions which can stand the changing nature of value systems over time; 
- Presentation of established methodologies (interviewing, perceptual mapping, cognitive mapping, etc.) upgraded/combined with new technologies and social networking media, as well as usefulness and real value of the new ICT and crowd-sourcing in revealing people's attitudes towards their living environments;

- The meaning of partnerships of different stakeholders-focused on local initiatives, residents, local and city authorities, urban planners, and other players-in maintaining a long-term and long-lasting cooperation forms for improving local public spaces;

- Presentation of research practices in public space that offer an investigation into different perceptions/attitudes of social groups.

The topic has been approached in a dialectical manner and conceived as a dynamic framework that allows for the exploration of various (relational) aspects of public spaces and urban cultures as well as those socio-theoretical approaches that critically investigate and shape them.

The paper by Maria Cerreta, Gaia Daldanise and Sabrina Sposito, Culture-led regeneration for urban spaces: Monitoring complex values networks in action, presents the basic idea of interdisciplinary innovative approach for culture-led urban regeneration policies and practices. In opening the discourse of new collaborative cultural regeneration of urban public spaces and places, the authors are questioning the new uses for public spaces to improve the engagement of communities and awake their self-activation for building complex values networks. The paper explores the new forms of local complex values networks in regeneration processes, based upon the evaluation of the selected Italian practices with the multi-criteria method PROMETHEE-GAIA.

The contribution by Matej Nikšič, Biba Tominc and Nina Goršič, Revealing residents' shared values through crowdsourced photography: Experimental approach in participatory urban regeneration, similarly addresses the issue of communities' shared values as a fundamental element in co-creation and implementation of shared future visions of local environments. In the case study of the aging planned residential neighbourhoods, the authors develop an innovative tool to reveal these values through the usage of digital photography with captions. They argue that photography is an appropriate communication tool between the two groups of actors that are deeply involved in the participatory process: the residents on the one hand and the planners on the other. Nonetheless, the authors caution that photography must be accompanied with certain other pre-defined elements that help to establish a common language between the two groups.

The paper by Elena Marchigiani, Accessibility to welfare spaces in council housing neighbourhoods of Trieste: Research at the interface of public policies and communities, also underscores the problems of the built environments erected Europe-wide after the Second World War, defined by large quantities of houses, community spaces, and facilities. Their current poor spatial quality is coupled to an increasing demand for public social and health assistance. The author stresses the need to re-orient local welfare from a quantitative and functionalist approach to the concept of welfare spaces and to a stronger attention to the qualities of services' physical setting. It presents the approach of an action research that was carried out in four peripheral neighbourhoods of Trieste, Italy.

Tomaž Pipan's paper, Interactive tangible planning support systems and politics of public participation, illustrates the duality of augmentations of cities through digital technology and the ever-more-present participation requirement in the urban planning processes. Digital technologies are presented as a promising technicality for an efficient running of the cities, while on the other hand the participatory agenda requires a more levelled playing field for 
different stakeholders and a wider consensus. The dilemma of connecting the digital city, unreadable to the public, with decision-makers and the specialized professionals with a consensus of all stakeholders in the planning process is central to the paper, which compares two examples of interactive tangible planning support systems.

Finding the "local green voice"? Waterfront development, environmental justice, and participatory planning in Gowanus, $\mathbf{N Y}$ is a contribution by Zeynep Turan that examines the question of polluted urban landscapes, vulnerable to climate-induced sea-level rise and inhabited by lower-income population. At the same time, these areas are faced with an arrival of newcomers, eager to exploit the waterfront property. The article charts the progress of neoliberal urban development in Gowanus through the lenses of critical urban theory, identifying stakeholders and power dynamics. It presents the usage of rezoning and revitalization in transforming an industrial business zone and low-income neighbourhood while coping with the issues of climate change and sea-level rise.

A discussion based on studying the urban-suburbs dichotomy is presented in the paper written by Boštjan Bugarič, Urban acupuncture treatment: Implementing communication tools with youth in Ljubljana suburbs. Urban acupuncture is presented as a valuable tool for placemaking, characterized as citizen-driven activities on small-scale, bottom up projects. These foster community building and motivate residents of neglected neighbourhoods to engage in place-making. Zalog, a suburb of Ljubljana, is taken as a case study of a successfully stimulated local participation. The paper shows how the needs of youngsters can be explored and evaluated, and how the residents can be encouraged to become active partners in the transformation of public space.

The paper by Sara Basso, Rethinking public space through food processes: Research proposal for a "public city", investigates the urban peripheries made up of council housing neighbourhoods that are frequently equipped with large open spaces, yet lack the public dimension in physical and social terms. The author discusses the redevelopment of the "public city" through rethinking the food-processes. Her useful insights serve as incentives to update planning tools and define new types of public spaces. The article pleads for innovative ways to activate cohesive social and economic relationship networks, vital to disruption of those mechanisms that lead to characteristics often affecting peripheral council housing neighbourhoods: isolation, closures, and marginality.

Sharing responsibilities to regenerate publicness and cultural values of marginalized landscapes: Case of Alta Irpinia, Italy, authored by Stefania Oppido, Stefania Ragozino, Serena Micheletti and Gabriella Esposito De Vita, looks at Italian non-core areas in order to investigate the role of the "landscape community" within the collaborative regeneration strategies in which the landscape could be considered the driver for the development. Authors present the case of Alta Irpinia in Southern Italy where successful bottom-up initiatives contributed to the reusing process of the historical Avellino-Rocchetta Sant'Antonio railway.

Matej NIKŠIČ, Urban Planning Institute of the Republic of Slovenia, Ljubljana, Slovenia (matej.niksic@uirs.si)

Stefania RAGOZINO, Institute for Research on Innovation and Services for Development CNR-IRISS, Naples, Italy(s.ragozino@iriss.cnr.it)

Alenka FIKFAK, University of Ljubljana, Faculty of Architecture, Ljubljana, Slovenia (alenka.fikfak@fa.uni-lj.si) 


\section{Acknowledgments}

This special issue was made possible in the context of the Europe-wide Human Cities project entitled Challenging the City Scale (www.humancities.eu), co-funded by the European Union Programme Creative Europe 2014-2020. The main aim of this project is to explore the ways in which local residents can reinvent cities through experimentation, applied research, and co-creation in urban spaces. A joint event was organized in Ljubljana in May 2017 by the Urban Planning Institute of the Republic of Slovenia and the Faculty of Architecture of the University of Ljubljana in cooperation with the AESOP's Thematic Group Public Spaces and Urban Cultures. The conference addressed the theoretical and practical approaches to urban regeneration through participatory regeneration of urban public space. Selected contributions are presented in this special issue, while others have already been published in Nikšič et al. (2017).

Special thanks go to the team of scholars of the AESOP Thematic Group Public Space and Urban Culture (http://www.aesop-planning.eu) that values a critical and constructive dialogue on the processes related to the series UNSTABLE GEOGRAPHIES - DISLOCATED PUBLICS (2016-2018) with an equal involvement of researchers and practitioners, locals and guests. It aims to explore and rethink relations between different concepts and meanings, related to both cities facing austerity, crises, and a variety of migration patterns as well as civic responses in the form of emerging practices of self-organization, social innovation, and planners' investments in building solidarity, hope, and trust. Special thanks go to Human Cities partners too who invested time, knowledge, energy and enthusiasm to make the whole project a success: FH Joanneum, Graz [AT]; CultureLab, Brussels [BE]; Pro Materia, Brussels [BE]; BEAZ/Bilbao-Bizkaia Design \& Creativity Council, Bilbao [ES]; Association of Estonian designers, Tallinn [EST]; Aalto University, Helsinki [FI]; Cité du design Saint-Etienne [FR]; Politecnico di Milano, Milan [IT]; Zamek Cieszyn [PL]; Design Week Belgrade [RS]; Urban Planning Institute of the Republic of Slovenia, Ljubljana [SI]; Clear Village, London [UK].

\section{References}

Abbot, J. (1996) Sharing the city. Community participation in urban management. London, Routledge.

Akkerman, T., Hajer, M. \& Grin, J. (2004) The interactive state: Democratisation from above? Political Studies, 52(1), pp. 82-95. DOI: 10.1111/j.1467-9248.2004.00465.x

Allmendinger, P. \& Haughton, G. (2011) Post-political spatial planning in England: a crisis of consensus? Transactions of the Institute of British Geographers, 37(1), pp. 89-103. DOI: 10.1111/j.14755661.2011.00468.x

Beebeejaun, Y. (ed.) (2016) Participatory city. Berlin, JOVIS Verlag.

Ertio, T. (2015) Participatory apps for urban planning-Space for improvement. Planning Practice \& Research, 30, pp. 303-321. DOI: 10.1080/02697459.2015.1052942

Hamilton, I., Dimitrovska-Andrews, K. \& Pichler-Milanović, N. (eds.) (2005) Transformation of cities in Central and Eastern Europe: Towards globalization. Tokyo, United Nations University Press.

Human Cities (2008) Celebrating public space. Available at: http://www.uirs.si/pub/humancities2010.pdf (accessed 17 Sept. 2018).

Human Cities (2010) Civil society reclaims public space. Cross perspectives based on research. Available at: http://www.uirs.si/pub/humancities2012.pdf. (accessed 17 Sept. 2018).

Human Cities (2014) Challinging the city scale. Accesible at: http://humancities.eu/story/now-availablechallenging-the-city-scale-2014-2018-investigation/ (accessed 17 Sept. 2018).

Madanipour, A. (2016) Culture and tolerance in public space. In: Moroni, S. \& Weberman, D. (eds.) Space and pluralism: Can contemporary cities be places of tolerance?, pp. 35-54. Budapest, Central European University Press.

Nikšič, M., Gautier, H., Ragozino, S., Mazurkiewicz, W. \& Fikfak, A. (eds.) (2017) Public spaces for local life: Shared values in diversified urban communities as a foundation for participatory provision of local public spaces; Book of contributions. Available at: http://humancities.uirs.si/portals/4/Joint\%20AESOP\%20and\%20Human\%20Cities\%20_\%20Ljubljana\%20 2017\%20_\%20Book\%20of\%20Contributions_1710.pdf (accessed 17 Sept. 2018).

Smith, F. M. (1999) Discourses of citizenship in transition: Scale, politics and urban renewal. Urban Studies, 36(1), pp. 167-187. DOI: 10.1080/0042098993808

Smith, N. (2002) New globalism, New urbanism: Gentrification as global urban strategy. Antipode - A radical journal of geography, 34(3), pp. 427-450.

Tasan-Kok, T. \& Baeten, G. (eds.) (2012) Contradictions of neoliberal planning: Cities, policies, and politics. London, Springer. DOI: 10.1007/978-90-481-8924-3 
Tewdwr-Jones, M. \&Thomas, H. (1998) Collaborative action in local plan-making: Planners' perceptions of 'planning through debate'. Environment and Planning B: Urban Analytics and City Science, 25(1), pp. 127-144.

Sennett, R. (2017) The open city. In: Haas, T. \& Westlund, H. (eds.) In the post-urban world: Emergent transformation of cities and regions in the innovative global economy, pp. 97-106. New York, Routledge. 